\title{
GEMINATE ATTRITION ACROSS THREE GENERATIONS OF FARSI-ENGLISH BILINGUALS LIVING IN CANADA: AN ACOUSTIC STUDY
}

\author{
Yasaman Rafat \\ The University of Western Ontario, CAN \\ Mercedeh Mohaghegh $^{* *}$ \\ University of Toronto, CAN \\ Ryan Stevenson $^{* * *}$ \\ The University of Western Ontario, CAN
}

\begin{abstract}
The main goal of this study was to determine whether the geminate-singleton consonant length contrast attrites across three different generations of Farsi-English-speaking bilinguals living in Canada. The secondary aim of the study was to shed light on the role of universal phonetic factors on the process of geminate-singleton length contrast attrition in the same population. The effect of manner/class of sounds and voicing was examined as predictors of geminate attrition in eight Farsi-English-speaking bilinguals living in Toronto forming three categories of generations: first generation, 1.5 generation and second generation. The 1.5 generation category distinguishes children of Iranian immigrants who had acquired Farsi as their first language and came to Canada between the ages of five to fourteen from second generation heritage speakers of Farsi. The productions of the bilinguals were compared with the productions of three homeland variety controls. A word-naming task, which included 108 words was conducted. Using Praat software, 2398 tokens were acoustically analyzed. Attrition was defined in terms of changes in mean duration of geminates relative to their singleton counterparts, percentage of geminate-singleton degemination, and category overlap. Mean durations were then analyzed using a 3-way, mixed-model, repeated-measures ANOVA. Results showed that geminates attrite across different successive generations. Moreover, there was some evidence to suggest that geminate realization across generations patterns with typological patterns previously reported, showing that universal phonetic principles such as aerodynamic constraints/articulatory difficulty and acoustic/perceptual salience also constrain geminate realization in bilingual Farsi-English speakers. However, there was no evidence to suggest that more marked geminates suffer a higher degree of attrition. This is the first study to examine the attrition of a typologically marked contrast, which considers the role of universal phonetic principles, markedness in an understudied bilingual community across different generations.
\end{abstract}

Keywords: Geminate; Attrition; Bilingualism; Phonetics; Phonology; Speech production; Farsi; English

\footnotetext{
${ }^{* *}$ Holds a PhD in Hispanic Linguistics from the University of Toronto. She is an Assistant Professor of Hispanic Studies (Linguistics) in the Department of Modern Languages \& Literatures at Western University. She works on second language and second dialect speech learning, orthographic processing, and bilingualism. Email: yrafat@uwo.ca

${ }^{* *}$ Holds a Ph.D. in Psycholinguistics from the University of Toronto and currently is a speech scientist at Nuance Communications, Inc. Her research interests are spoken word recognition, speech perception, phonetics and second language acquisition. Email: mercedeh.mohaghegh@mail.utoronto.ca

${ }^{* * *}$ Holds a PhD in Psychological and Brain Sciences from Indiana University, an NIH-funded postdoctoral fellowship from Vanderbilt University Medical Center, and a Banting postdoctoral fellowship from the University of Toronto. He is currently an assistant professor in the Brain and Mind Institute and Department of Psychology at Western University. Email: rsteve28@uwo.ca
} 


\section{Introduction}

Although there is a rich body of literature on second language (L2) speech learning (e.g., Best \& Tyler, 2007; Brown, 1998; Colantoni \& Steele, 2008; Flege, 1997), less is known about phonetic and phonological attrition in bilinguals' first language (L1) (e.g., Celata \& Cancila, 2010; Mennen, 2004; Mennen, Mayr \& Price, 2011; Ulbrich \& Ordin, 2015; Cao, 2016). The majority of the research on $\mathrm{L} 1$ attrition has focused on the lexicon and morpho-syntax (Schmid, 2002) and there is a dearth of evidence on phonological attrition (Bullock and Gerfen, 2004). The main goal of this acoustic study is to determine the degree to which the geminate-singleton length contrast may undergo attrition across different generations of Farsi-English bilinguals living in Canada. The secondary aim of this study is to shed light on the potential role of the universal phonetic factors of manner and voicing as predictors of geminate attrition. Some languages use length as a contrastive feature where a long/geminate sound is meaningfully distinct from a shorter/singleton counterpart. Whereas L1 attrition in the perception of geminate consonants in Italian-American communities has been reported by Celata and Cancila (2010), there are no previous studies that have reported geminatesingleton length contrast attrition in the production of bilingual immigrant communities. Because gemination is a relatively uncommon marked phenomenon, the extent of previous work done in geminate attrition is limited. While the role of universal phonetic factors has been previously examined in L2 phonological acquisition (e.g., Colantoni \& Steele, 2007, 2008) and L2 geminate production (Sorianello, 2014), to the best of our knowledge, no previous studies that have specifically focused on the role of such factors with respect to L1 phonological attrition in bilinguals.

We will examine $\mathrm{L} 1$ geminate attrition in the production of three generations: (1) first generation immigrants, (2) 1.5 generation immigrants (Chung, 1997; Rumbaut, 2004; Tan, 2016) and (3) second generation immigrants. First generation immigrants are those who came to Canada in adulthood. Previous studies have examined the opposition between first- and the second-generation bilinguals. Although age of arrival has been previously examined as a predictor of attrition (e.g., De Leeuw, Mennen, \& Scobbie; 2013), the 1.5 generation has not truly been taken into consideration as a separate category. In this study, we have included the 1.5 generation, which is considered a distinct category in the sociocultural literature (Rumbaut, 2004). This group typically consists of children of immigrant families that arrived between the ages of 5 and 14 to the host country. Raumbat (2004) describes them as 'bridge-builders' and 'cultural interpreters' for the first generation, and more bi-cultural and bilingual than the first and second generations. Tan (2016) similarly states that the 1.5 generation have stronger ties to their heritage culture than second-generation immigrants but not quite to the level of first-generation immigrants. The second generation in the current study consisted of children of immigrants who were either born or arrived before the age of 5 in an English-speaking country. To the best of our knowledge, including the 1.5 generation category is a novel way of categorizing different generations of immigrants in attrition studies.

\section{L1 phonetic and phonological attrition in bilinguals}

Abundant evidence has shown that different aspects of L1, including morphology and syntax can undergo attrition (for a more detailed discussion see Köpke \& Schmid, 2004). Specifically, the research focusing on L1 phonetic attrition in bilinguals has been growing (e.g., Celata \& Cancila, 2010; Flege, 1987; Guion, 2003; Major, 1992; Mayr, Price \& Mennen, 2012). Phonetic drift in L1 toward the L2 sounds is evidenced in temporal (e.g., Chang, 2012; Flege, 1997; Major, 1992) and spectral aspects of consonant production (Chang, 2012; Peng, 1993; Ulbrich \& Ordin, 2014), vowel production (Chang, 2012; Baker \& Trofimovich, 2005; Flege, 1987; Guion, 2003), consonant perception (Celata \& Cancila, 2010), and in intonational features (Mennen, 2004).

Flege (1997) was one of the first studies to provide evidence of assimilation of the L1 and L2 phonetic categories. He found changes in the Voice Onset Time 
(VOT) of French-English and English-French adult bilinguals, where VOT values for French / $t$ / for both groups were longer than those of their monolingual counterparts. On the other hand, VOT values for English / $t$ / were shorter than their average native values, again for both groups. Likewise, the second formant frequency (F2) for the vowel $/ \mathrm{u} /$ was lower than their native French counterparts for the French group but not for the English group. However, /y/ was produced in a native-like manner by the participants. The results confirmed the predictions that $/ \mathrm{u} /$ and $/ \mathrm{t} /$ would be classified as sounds in phonetic categories that already exist in the L1 and /y/ as a sound that is different from an existing category in the L1. Major (1992) also examined VOT values in Brazilian-English bilinguals in the U.S. and similarly to Flege (1997) found evidence of mutual L1-L2 interaction, supporting Flege's (1995) Speech Learning Model (SLM).

VOT drifts in /p,t,k/ in L1 of bilinguals have also been examined from a sociolinguistic point of view in Hrycyna, Lapinskaya, Kochetov and Nagy (2011). A drift towards English VOT values was reported in successive generations (first, second, and third generation) of Italian-, Russian-, and Ukrainian-English bilingual communities. They also reported differences between the language groups and suggested that social factors, such as (i) the cohesiveness of a community, that would suggest having enough opportunity for casual speech, (ii) the size of a community, and (iii) attitude towards a particular variety of a language may be responsible for the between-group differences.

Although VOT remains one of the best-studied phenomena in studies that have examined the bidirectionality of language influence on speech production, recently there has been a growing interest in examining a phonetic shift in other aspects of L1. De Leeuw, Mennen and Scobbie (2012) examined the change in the production of the lateral phoneme /1/ in the L1 German of late German-English bilingual speakers living in Canada. They found that the F1 and F2 values of the German /1/ of their bilinguals differed from their native German counterparts and showed a shift towards English. Furthermore, there was a high degree of variability both within and between bilinguals, and not all the participants exhibited this change. They proposed a dynamic system theory: maturational constraints cannot be the only cause of attrition, and that various predictors which influence language development in individuals must be considered.

While there have been no production studies on L1 geminate attrition, previously Celata and Cancila (2010) investigated the perception of the geminate-singleton contrast in native speakers of Lucchese Italian and among first generation late Lucchese Italian-English bilinguals (those who emigrated to the U.S.) and second generation Lucchese Italian bilinguals (those who were born in the U.S.). The results of a real word and a nonce word identification task revealed that bilingual speakers are significantly worse than the control Lucchese monolongual speakers at the perception of the geminate-singleton contrasts. In particular, the second generation group exhibited a higher degree of attrition than the first generation group. Therefore, the authors concluded that the perception of the length contrast has become progressively impaired in their bilingual groups. Given the scarcity of evidence of attrition in bilingual speech at the phonological level, and the fact that gemination has not been previously examined in production studies of phonetic or phonological attrition in these languages, we will examine the attrition of L1 geminate-singleton length contrast in Farsi-English speaking bilinguals living in Canada. To the best of our knowledge, there are no previous studies that have examined attrition in Farsi-English bilinguals.

\section{Geminate consonants across the languages of the world}

A length contrast between singleton (short) and geminate (long) consonants is observed in 3.3\% of the world's language (Maddieson, 1984). ${ }^{1}$ Therefore, gemination is considered a marked phonological phenomenon. Some examples of languages where there is a binary contrast (i.e., short and long consonants are phonologically contrastive) include Italian (Payne, 2005; Celata and Cancila, 2010), Arabic (Hassan \& Payne, 2008; Khattab \& Al-Tamimi, 2014), Farsi (Persian) (e.g., Hansen, 2004; Rafat, 2008, 2010), and some Indonesian 
languages such as Buginese, Madurese and Toba Batak (Cohn, Ham \& Podesva, 1999). Geminates also exist in Inari Sami and Finnic languages such as Estonian, where there is a ternary (three-way) contrast (Markus et al., 2012).

Gemination does not affect all consonants equally and is motivated by complex phonetic processes (e.g., Blevins, 2004; Podesva, 2002; Steriade, 1982; Taylor, 1985). Both acoustic/perceptual salience and articulatory/aerodynamic difficulty can predict geminate occurrence. For these reasons, geminates are most likely to occur in obstruents, in particular in voiceless obstruents. Voiced obstruents are not as common as their voiceless counterparts (Hayes and Steriade 2004; Jaeger 1978; Ohala 1983; Taylor 1985) because of a phonetic restriction, namely the difficulty to maintain a sufficient transglottal air pressure drop to produce voicing with a long closure. In general, voicing is a good predictor of degemination whereby voiced sounds are more likely to be reduced from a geminate to a singleton (e.g., Elmedloui, 1993; Kawahara, 2007). Geminate fricatives are more marked than their noncontinuant obstruent counterparts (i.e., stops and affricates). There are no languages that have geminate fricatives but lack geminate stops (e.g., Taylor, 1985). Obrecht (1965) attributes the markedness of geminate fricatives to the fact that fricatives are high-frequency information-bearing components (e.g., plurality) but the information is less reliably transmitted in speech. Sonorant geminates are the most marked class of geminates. This is attributed to sonorancy making the duration contrast harder to perceive (e.g., Taylor, 1985; Podesva, 2002; Kawahara, 2007). Kawahara (2007) proposes that sonorant consonants cannot acoustically signal their duration as well as other sounds because of blurry formant transitions into and out of flanking vowels.

In L2 production, phonetic universals, and implicational principles also affect geminate consonant realization. Sorianello (2014) examined the production of Italian geminates by German-, Spanish- and Chinesespeaking learners of Italian. Specifically, manner of articulation, voicing, and stress affected L2 geminate consonant production, albeit manner of articulation and voicing were better predictors of gemination than stress. Subsequently, they reported that gemination was more likely to occur with voiceless stops, and degemination with sonorant consonants.

\section{Gemination in Farsi and English}

Length is contrastive in Farsi/Persian (e.g., Hansen, 2004; Rafat, 2010). For example, /æjar/ 'carat' contrasts with /æj:ar/ 'brave.'. Lucchese Italian demonstrates clear evidence of degemination (e.g., Celata \& Cancila, 2010), however previous evidence regarding geminate variation in Farsi is mixed. Mahootian (1997) reported degemination in words of Arabic origin, but Hansen (2004) did not provide any evidence of geminate-singleton overlap in stops. Rafat (2010) also examined geminate rhotic production and found that degemination was only found word-finally. Therefore, the geminate-singleton contrast appears to be preserved word-medially in Farsi.

While gemination is contrastive in Farsi, it is noncontrastive in English (e.g., Ladefoged, 1999; Roach, 2000; Wolfram \& Schilling-Estes, 1998). However, phonetic lengthening has been reported to take place in English when identical segments are realized at the morpheme or word boundary (concatenated geminates; e.g., Bailey, 1983; Delattre, 1968; Kaye, 2005). Examples of concatenated germination are night time and makes sense. Given that English and Farsi behave differently with respect to gemination, it is plausible to believe that geminate change might take place in Farsi-English-speaking bilinguals because of contact with the English language.

\section{Research questions and predictions}

Given the scarcity of research on L1 phonological attrition on the geminate-singleton length contrast in bilingual speech, we thus looked into the following three questions:

1. Do geminate consonants undergo attrition in the production of Farsi-English-speaking bilinguals living in Canada? 
2. Does the degree of attrition increase across generations (first, 1.5 and second generation) (Hrycyna et al., 2011)? In other words, is generation a predictor of the degree of geminate-singleton consonant length attrition?

3. Are manner of articulation (Blevins, 2004; Podesva, 2002; Steriade, 1982; Taylor, 1985; Sorianello, 2014) and voicing (Jaeger 1978; Ohala 1983; Taylor 1985; Elmedlaoui, 1993; Hayes and Steriade 2004; Kawahara, 2007) also predictors of geminatesingleton consonant length attrition?

The hypotheses in this study are as follows:

H1: Because L1 attrition has previously been observed in the perception of geminates in an Italian-American community living in the U.S. (Celata \& Cancila, 2010), it is predicted that geminates also manifest a temporal reduction and degemination or category overlap with singletons in the speech of Farsi-English-speaking bilinguals living in Canada.

$\mathrm{H} 2$ : The following hierarchy is predicted with respect to the overall mean duration differences across the three generations, in which the mean geminate consonant duration shows a decrease and the percentage degemination/category overlap shows an increase from first generation to second generation: first $>1.5$ $>$ second.

H3 (i): Class of sounds, specifically manner of articulation (Steriade, 1982; Taylor, 1985; Podesva, 2002; Blevins, 2004), will be a predictor for the temporal reduction and percentage degemination/ category overlap. In particular, the following hierarchy will be attested, in which mean consonant duration will increase and percentage degemination/category overlap will decrease from left to right across generations: sonorants $>$ fricatives $>$ non-continuant obstruents.

H3 (ii): Voicing (e.g., Jaeger, 1978; Ohala, 1983; Taylor, 1985; Elmedlaoui, 1993; Hayes \& Steriade, 2004; Kawahara, 2007) is predicted to condition geminate-singleton length contrast attrition, in which voiceless geminate consonants will exhibit a lower degree of temporal reduction and a higher percentage of degemination/category overlap than their voiced counterparts across generations.

\section{Methods}

\subsection{Participants}

Eleven participants including 8 bilinguals and 3 Farsi-speaking monolinguals, whose ages ranged from 30-66, took part in the study (see Table 1 in the appendix). Three of the eleven participants were monolingual controls. A language background questionnaire at the end of the session determined the generation class of the eight bilingual participants. The three generations were first, 1.5 , and second generation. First generation immigrants are those who came to Canada in adulthood. The 1.5 generation consisted of children of Iranian immigrant families that arrived between the ages of 5 and 14. The second generation consisted of children of Iranian immigrants who were either born or arrived before the age of 5 in an Englishspeaking country. The first-generation participants consisted of two balanced Farsi-English bilinguals and a Farsi-dominant bilingual, born in Iran, who lived in Toronto, Canada. Their ages of arrival were 20, 40, and 43 . The 1.5 generation participants in this study were two English-dominant bilinguals who also lived in Canada. Their ages of arrival were 11 and 13. The second-generation participants were two Englishdominant bilinguals, born in London, England, who had resided both in England and in Canada but never in Iran, as well as an English-dominant bilingual, who had arrived in Canada at the age of 4 . All participants spoke the same variety of Farsi at home, namely Tehrani Farsi. The control group which used the homeland variety included three monolingual Tehrani Farsi-speakers who were born in Iran, lived in Iran and were visiting Canada at the time of the experiment. They had low proficiency in English. 


\subsection{Stimuli}

The data presented here are a subset of a larger study, in which data had also been collected on two wordreading tasks. Given that one of the second generation and one of the 1.5 generation participants were not able to read in Farsi fluently, only the data collected for the word-naming task is presented here. The stimuli consisted of 108 bi- (e.g., /a.'dii / 'normal') and tri-syllabic (e.g., /mo.næ.'z:æm/ 'neat'), frequent Persian words, based on the intuition of the first and second author. The words were of both Persian and Arabic origins. There were a total of 69 geminates and 39 singletons. Both geminate and singleton words included non-continuant obstruents (/b,d,p,t,k,G,tf,b/), fricatives (/f, v,s, $/)$ and sonorants $(/ \mathrm{m}, \mathrm{n}, \mathrm{r}, \mathrm{l}, \mathrm{j} /)$. Geminates mostly occurred in stressed syllables (e.g., /pe.'l:e/ 'stairs') . There were also 14 distracters to divert participants' attention from the main goal of the experiment. Because the main stimuli consisted of bisyllabic and trisyllabic, the distractor items included monosyllabic words such as (/ab/ 'water') so that any potential effect of encountering a common pattern would be cancelled out.

\subsection{Procedure}

All participants completed a word-naming task in Farsi and a language background questionnaire. The participants were told that the purpose of the experiment was to test their vocabulary knowledge in Farsi. They were instructed to guess the words the interviewer was asking a question about, speak naturally and at a normal speech rate. The words were elicited by asking each participant a list of questions in Tehrani Farsi. For example, to elicit the word for /ræ.'G:as/ 'dancer', participants were asked in Farsi: "What do we call a person that dances?" The word-naming task was repeated three times. Participants were given a two-minute break between each round of questions. All participants filled out a background questionnaire, upon the completion of the recordings.

The sessions all took place in a quiet place and lasted between an hour to an hour and a half. Participants were recorded individually using an M-Audio Micro- track 24/96 professional two-channel mobile digital recorder and a lavaliere unidirectional microphone. The recordings were made at a sampling rate of 44.2 $\mathrm{kHz}$ and a quantization rate of 16 bits. The audio files containing the extracted tokens were down- sampled at $22.1 \mathrm{kHz}$ and saved in wave format.

\section{Data analysis}

A total of 2398 tokens were analyzed acoustically using Praat (V. 5.3.23); Boersma \& Weenink, 2012). We measured duration of consonants for all groups and compared any 'differences / temporal reduction' across the four participant groups. We also examined the data for evidence of 'complete degemination/category overlap', in which geminates fell in the same duration range as their singleton counterparts.

To analyze sound duration, speech waveforms and spectrograms were inspected in Praat. Figure 1 exemplifies the duration decrease observed in the spectrograms for the word /æm: $\varepsilon /$ 'aunt' across each successive generation. 
a)

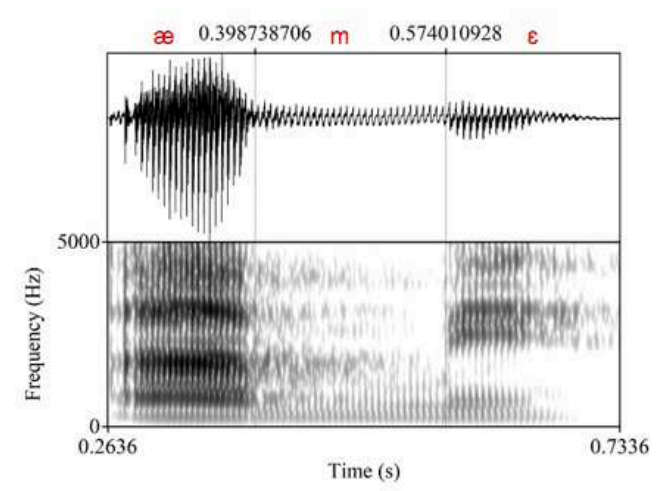

c)

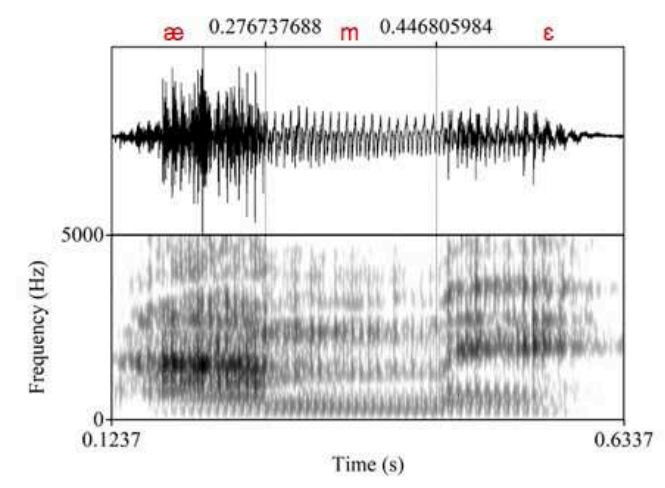

Figure 1. Sample waveforms and spectrograms of the word /æm: $\varepsilon /$ 'aunt'. The area within the two dotted lines indicates the interval corresponding to the duration of the geminate consonant $/ \mathrm{m}: /$ in a token produced by a participant from: a) the control group (176 ms); $b$ ) the first-generation group $(198 \mathrm{~ms}) ; c)$ the 1.5-generation group (170 ms); $d)$ the second-generation group (139 ms).

Duration of the singleton and geminate consonants was measured from the onset of the consonant up to its offset. For stops, these points matched with the onset of the stop closure and the offset of the stop release burst or aspiration noise respectively. For nasals, the measuring interval was determined from the onset of the nasal murmur up to the oral closure release. For fricatives, the onset and offset of the frication noise (aperiodicity) and for liquids, the onset and offset of the changes in the spectrum shape and amplitude of formant frequencies were the indicators of consonant duration interval. b)

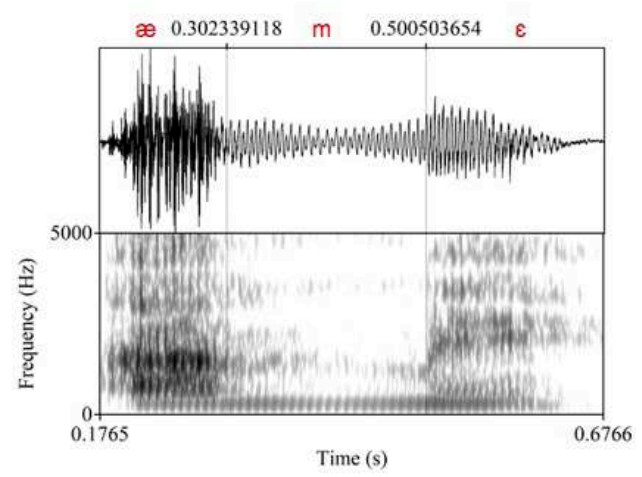

d)

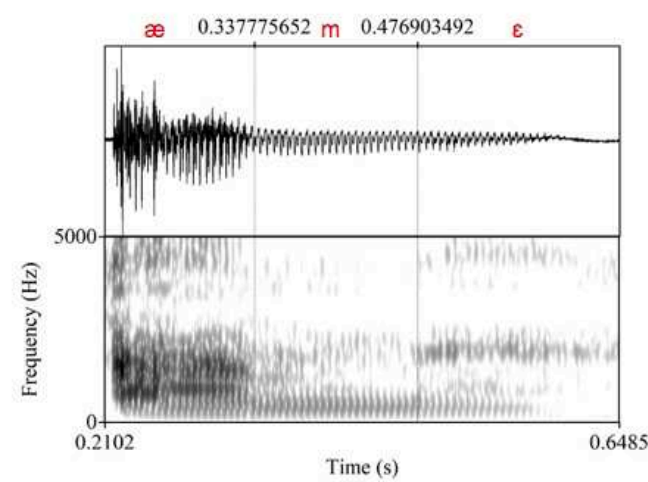

\subsection{Statistical analysis - mean duration}

Each participant's data were first split into trials based on manner and geminate-singleton contrast, and mean duration was calculated for each individual within each condition. Mean durations were then analyzed using a 3-way, mixed-model, repeatedmeasures ANOVA, with manner (sonorant, fricative, and obstruent) and geminate-singleton contrast as within-subject factors, and generation (homeland, first generation, 1.5 generation, and second generation), as a between subject factor. Greenhouse-Geisser corrections was used for all ANOVAs.

Given the findings of significant interactions with the between-subject factor of generation, a multiple regression was conducted with predictors including all variables showing an interaction with generation. While the current sample size is relatively underpowered for a multiple regression, this serves as an exploratory analysis including a more nuanced, continuous variable age of arrival (the age at which a given participant immigrated) in place of the categorical variable generation. 
The second series of analyses explored the possible impact of voicing on the results of the first analysis. Sonorants are, as mentioned above, always voiced, introducing a possible confound in comparison to fricatives and obstruents, which can be both voiced and voiceless. To address this, each participant's data were split into trials based on voicing and geminatesingleton contrast, and mean durations were calculated for each individual in each condition (collapsed across manner). Mean durations were then analyzed using a 3-way, mixed-model, repeated-measures ANOVA, with voicing (voiced and voiceless) and geminate-singleton contrast as within-subject factors, and generation (homeland, first generation, 1.5 generation, and second generation), as a between subject factor.

Following significant effects of voicing, the initial 3-way ANOVA and multiple regression were replicated including only voiced data, such that the voicing of sonorants was matched in the fricative and obstruent conditions.

\subsection{Statistical analysis - overlap}

In addition to analyzing mean durations with each condition, the overlap of duration between singletons and geminates for each consonant was calculated on an individual basis. The overlap of each consonant was measured relative to the overall range of durations associated with that consonant using the equation:

$$
\frac{\operatorname{Max}_{\text {singleton }}-\operatorname{Min}_{\text {geminate }}}{\operatorname{Max}_{\text {overall }}-\text { Min }_{\text {overall }}} \quad X 100 \%
$$

In which $\operatorname{Max}_{\text {singleton }}$ represents an individual's longest duration pronunciation of a given consonant as a singleton, and $\mathrm{Min}_{\text {geminate }}$ represents an individual's shortest duration pronunciation of a given consonant as a geminate. Thus, the numerator represents the absolute overlap in $\mathrm{ms}$. Max $\mathrm{overall}_{\text {ll }}$ represents an individual's longest duration pronunciation of a given consonant as either a singleton or a geminate, and $\mathrm{Min}_{\text {overall }}$ represents an individual's shortest duration pronunciation of a given consonant as either a singleton or a geminate. Thus, the denominator represents the full range of the consonant duration in ms. As such, positive values are indicative of an overlap in durations between singletons and geminates, and negative numbers are indicative of complete category segmentation such that the longest singleton durations are still shorter than the shortest geminate production.

Overlaps were then analyzed using a 2-way, mixedmodel, repeated-measures ANOVA, with manner (sonorant, fricative, and obstruent) as a within-subject factors, and generation (homeland, first generation, 1.5 generation, and second generation), as a between subject factor. Greenhouse-Geisser corrections were used for all ANOVAs. An identical, follow-up ANOVA was then conducted including only voiced consonants to account for the impact of sonorants which are always voiced.

\section{Results}

\subsection{The impact of generation on singleton and geminate duration}

The initial 3-way ANOVA exploring the impact of generation, manner, and geminate-singleton contrast on duration (see Data Analysis section for details), yielded significant main effects of manner $\left(\mathrm{F}_{(1.60,11.19)}=74.29, \mathrm{p}\right.$ $\left.<0.001, \eta_{\mathrm{p}}{ }^{2}=0.91\right)$, geminate-singleton contrast $\left(\mathrm{F}_{(1,7)}=\right.$ 239.63, $\left.\mathrm{p}<0.001, \eta_{\mathrm{p}}{ }^{2}=0.97\right)$, and generation $\left(\mathrm{F}_{(3,7)}=4.29\right.$, $\left.\mathrm{p}=0.05, \eta_{\mathrm{p}}{ }^{2}=0.65\right)$ (Figure 2). A significant two-way interaction was observed between geminate-singleton contrast and generation such that homeland and first generations showed a larger effect of geminate-singleton contrast than 1.5 and second generation individuals $\left(\mathrm{F}_{(3,7)}\right.$ $\left.=4.33, \mathrm{p}=0.05, \mathrm{\eta}_{\mathrm{p}}^{2}=0.65\right)$. Additionally, a significant two-way interaction was observed between manner and geminate-singleton contrast, with sonorants showing the largest difference between singletons and geminates $\left(\mathrm{F}_{(1.46,10.22)}=47.83, \mathrm{p}<0.001, \eta_{\mathrm{p}}{ }^{2}=0.87\right)$. No significant two-way interaction was observed between manner and generation $\left(\mathrm{F}_{(1.60,11.18)}=0.46, \mathrm{p}=0.79, \eta_{\mathrm{p}}{ }^{2}=0.16\right)$, and no significant three-way interaction was observed $\left(\mathrm{F}_{(4.38,10.22)}\right.$ $=1.27, \mathrm{p}=0.35, \eta_{\mathrm{p}}^{2}=0.35$ ).

To test whether the geminates followed the previously reported consonant duration hierarchy 
(sonorant $<$ fricative $<$ non-continuant obstruents), paired sample t-tests were conducted between each condition. Geminate sonorants were found to be significantly shorter than geminate fricatives $\left(\mathrm{t}_{(10)}=\right.$ 6.40, $\left.\mathrm{p}=7.87 \mathrm{e}^{-5}, \mathrm{~d}=1.17\right)$ and non-continuant obstruents $\left(\mathrm{t}_{(10)}=12.54, \mathrm{p}=1.92 \mathrm{e}^{-7}, \mathrm{~d}=2.11\right)$, and geminate fricatives were shorter than non-continuant obstruents $\left(\mathrm{t}_{(10)}=5.44, \mathrm{p}<2.83 \mathrm{e}^{-4}, \mathrm{~d}=0.76\right)$.
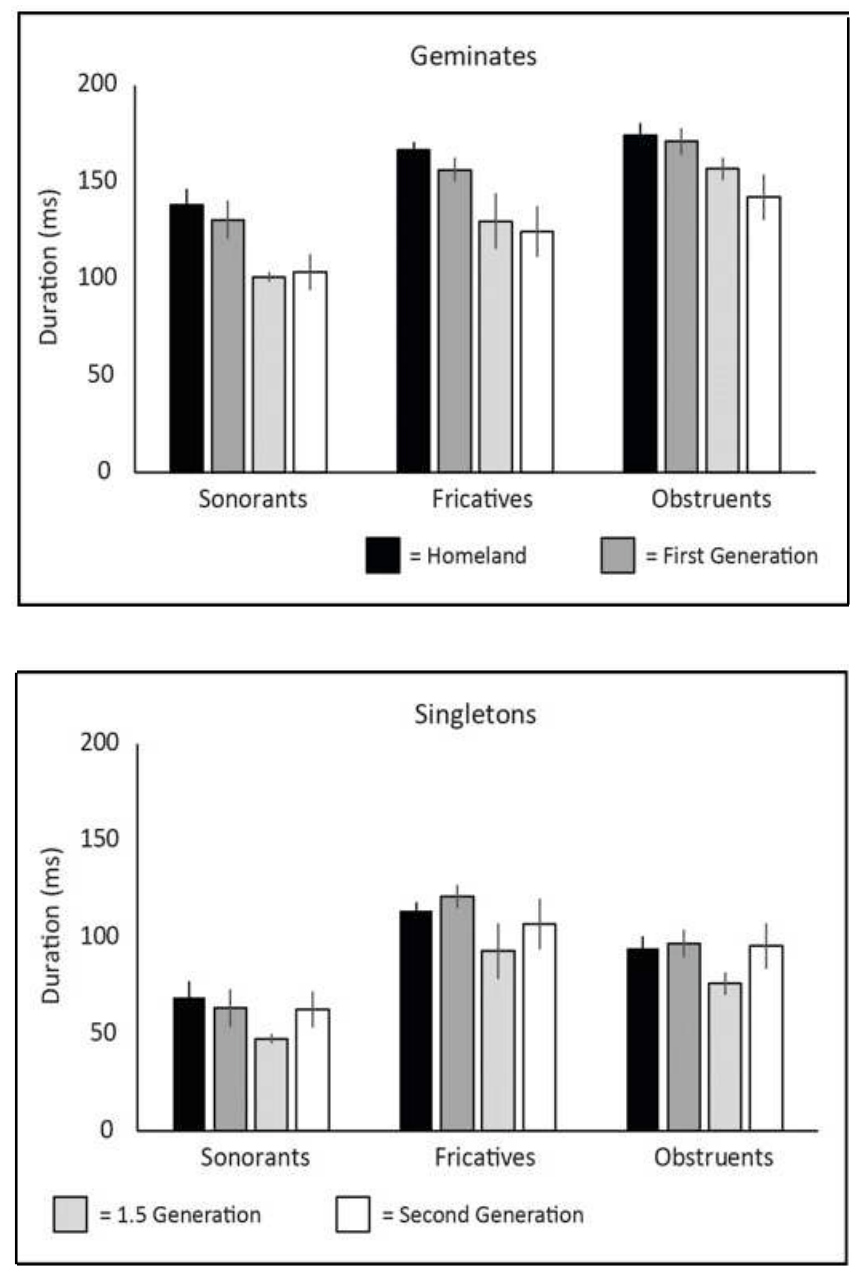

Figure 2. The impact of generation on mean duration. Mean consonant durations are depicted for geminates (left panel) and singletons (right panel), separated by manner. Mean duration decreased across successive generations, and did so more for geminates than for singletons. Error bars represent standard error.

Following up on the significant interaction between generation and geminate-singleton contrast, an exploratory multiple regression was conducted with duration, age of arrival, and an interaction variable as predictors of mean duration. Age of arrival was calculated as the chorological age of each individual upon arrival in Canada, and thus the homeland group was omitted. Using this more nuanced, continuous variable to describe age of arrival, results largely reflected the ANOVA using categorical age-of-arrival descriptors. The total model significantly predicted mean duration $\left(\mathrm{R}^{2}=0.56, \mathrm{~F}_{(3,44)}=18.79 . \mathrm{p}<0.001\right)$. Age of arrival was found to be a significant predictor $(\beta=0.21, t=2.13, p=$ 0.04 , partial- $\mathrm{R}=0.31$ ), as was geminate-singleton contrast $(\beta=0.57, \mathrm{t}=3.99, \mathrm{p}<0.001$, partial- $\mathrm{R}=0.40)$. The interaction here was not significant, but trended in the same direction as the ANOVA ( $\beta=0.19, \mathrm{t}=1.34$, $\mathrm{p}$ $=0.19$, partial $\mathrm{R}=0.20$ ), with younger generations showing a smaller difference between duration of singletons and geminates (see Figure 3).

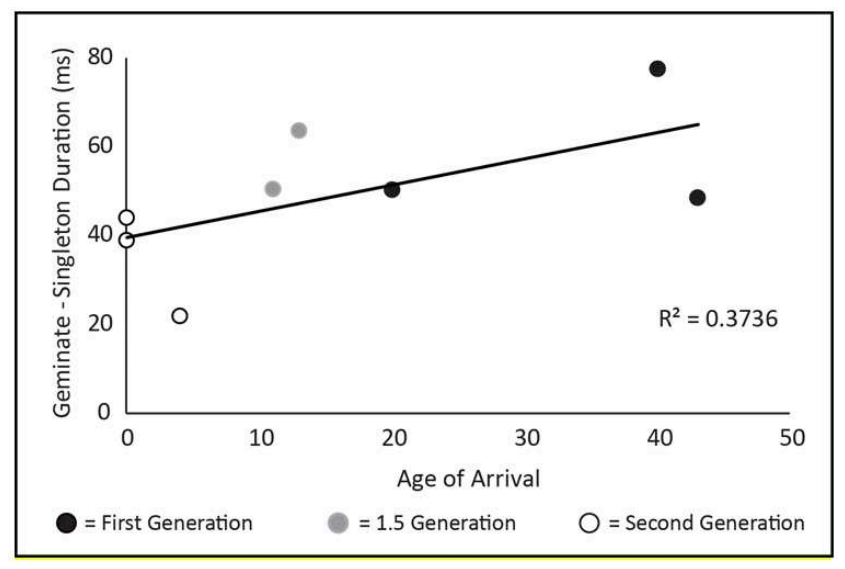

Figure 3. Age of arrival marginally predicts geminate-singleton differences in duration. The earlier the age at which an individual immigrated, the more attrition was observed, and the smaller the difference between geminate and singleton duration.

\subsection{The impact of voicing}

To test whether the voicing difference between sonorants and both fricatives and non-continuant obstruents influenced the original findings, data were segregated according to voicing, and a three-way ANOVA (voicing $\mathrm{X}$ geminate-singleton $\mathrm{X}$ generation) was conducted. Most importantly, voicing showed a significant main effect $\left(\mathrm{F}_{(1,7)}=290.38, \mathrm{p}<0.001\right.$, $\left.\eta_{\mathrm{p}}{ }^{2}=0.98\right)$, with voiceless consonants exhibiting longer durations than voiced, as expected (Figure 4). Additionally, main effects of geminate-singleton $\left(\mathrm{F}_{(1,3)}\right.$ $\left.=328.42, \mathrm{p}<0.001, \eta_{\mathrm{p}}{ }^{2}=0.98\right)$ and generation $\left(\mathrm{F}_{(3,7)}=\right.$ 
$\left.4.82, \mathrm{p}=0.04, \eta_{\mathrm{p}}^{2}=0.67\right)$, and a marginally significant two-way interaction between generation and geminatesingleton contrast $\left(\mathrm{F}_{(3,7)}=4.05, \mathrm{p}=0.06, \eta_{\mathrm{p}}^{2}=0.63\right)$ were observed in accordance with the previous analysis. No interactions were observed with voicing, including voicing by generation $\left(\mathrm{F}_{(1,7)}=0.01, \mathrm{p}=0.99, \mathrm{\eta}_{\mathrm{p}}{ }^{2}<0.01\right)$, voicing by geminate-singleton contrast $\left(\mathrm{F}_{(1,7)}=0.57, \mathrm{p}\right.$ $\left.=0.48, \eta_{\mathrm{p}}^{2}=0.08\right)$, and voicing by geminate-singleton contrast by generation $\left(\mathrm{F}_{(3,7)}=0.87, \mathrm{p}=0.50, \mathrm{\eta}_{\mathrm{p}}{ }^{2}=0.27\right)$.

Whilenointeraction between voicing and geminatesingleton contrast was observed, to conservatively ensure that voicing impacts both singletons and geminates, repeated-measures ANOVAs were run on each independently. When including only singletons, voicing still exhibited a significant effect $\left(\mathrm{F}_{(3,7)}=28.53\right.$, $\left.\mathrm{p}=0.001, \eta_{\mathrm{p}}{ }^{2}=0.80\right)$. Similarly, when including only geminates, voicing exhibited a significant effect $\left(\mathrm{F}_{(3,7)}=\right.$ 44.75, $\mathrm{p}<0.001, \eta_{\mathrm{p}}^{2}=0.87$ ).
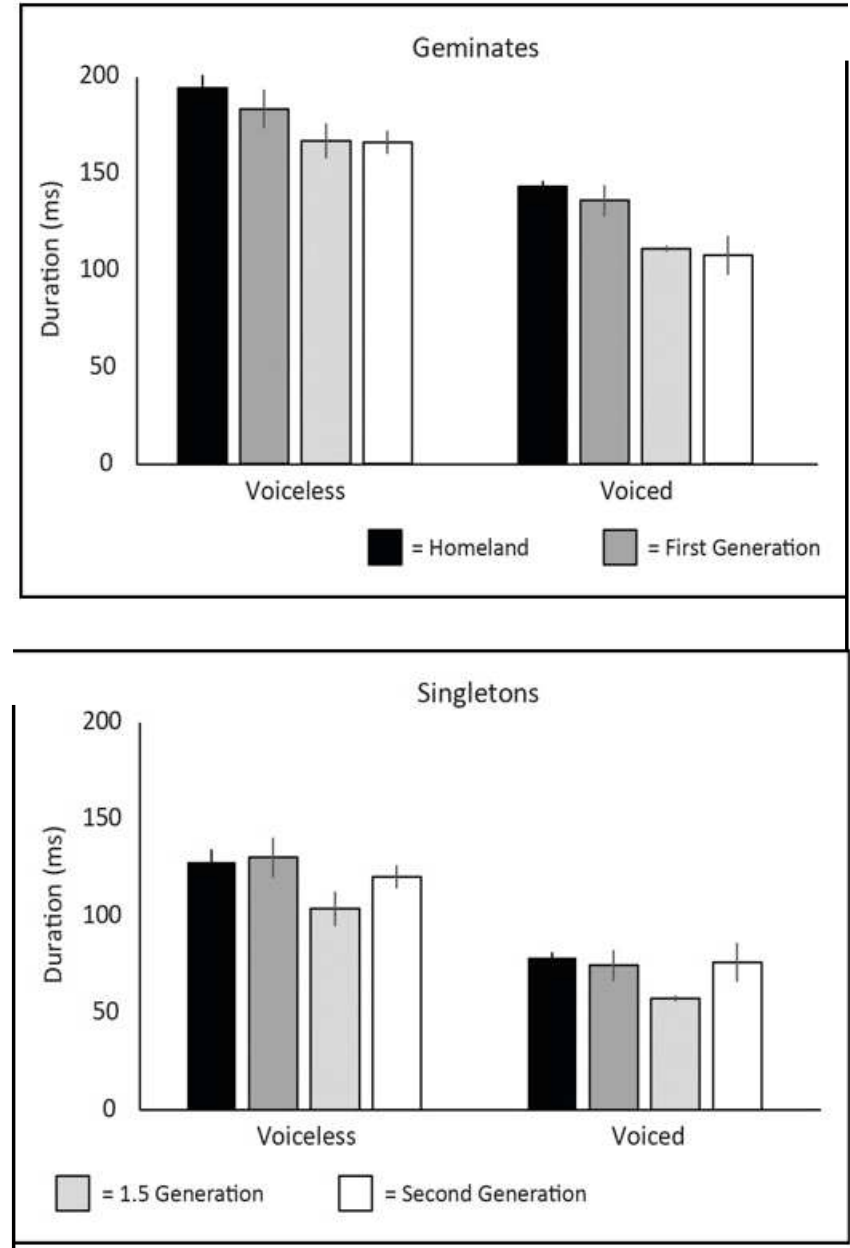

Figure 4. The impact of voicing on mean duration. Mean consonant durations are depicted for geminates (left panel) and singletons (right panel), separated by voicing. Mean duration was longer for voiced relative to voiceless consonants decreased across successive generations, and did so more for geminates than for singletons. Error bars represent standard error.

\subsection{The impact of generation on singleton and geminate duration controlled for voicing}

To control for inherent voicing differences between sonorants and both fricatives and non-continuant obstruents, all voiceless consonants were removed, and a second 3-way ANOVA exploring the impact of generation, manner, and geminate-singleton contrast on duration was conducted (see Analysis for details). This analysis yielded significant main effects of manner $\left(\mathrm{F}_{(1.60,8.97)}=21.69, \mathrm{p}=0.001, \eta_{\mathrm{p}}^{2}=0.76\right)$, geminatesingleton contrast $\left(\mathrm{F}_{(1,7)}=153.09, \mathrm{p}<0.001, \mathrm{\eta}_{\mathrm{p}}{ }^{2}=0.96\right)$, and generation $\left(\mathrm{F}_{(3,7)}=6.82, \mathrm{p}=0.02, \mathrm{\eta}_{\mathrm{p}}^{2}=0.75\right.$; see Figure 5). The significant two-way interaction observed between geminate-singleton contrast and generation in the original ANOVA was only marginally significant when controlling for voicing, but trended in the same direction, such that homeland and first generations showed a larger effect of duration than 1.5 and second generation individuals $\left(\mathrm{F}_{(3,7)}=3.49, \mathrm{p}=0.08, \eta_{\mathrm{p}}{ }^{2}=\right.$ $0.60)$. Additionally, a significant two-way interaction was observed between manner and geminate-singleton contrast $\left(\mathrm{F}_{(1.80,12.60)}=41.50, \mathrm{p}<0.001, \eta_{\mathrm{p}}{ }^{2}=0.86\right)$. No significant two-way interaction was observed between manner and generation $\left(\mathrm{F}_{(3.85,8.97)}=0.45, \mathrm{p}=0.76, \eta_{\mathrm{p}}{ }^{2}\right.$ $=0.16)$, and no significant three-way interaction was observed $\left(\mathrm{F}_{(1.33,12.60)}=1.11, \mathrm{p}=0.31, \eta_{\mathrm{p}}{ }^{2}=0.36\right)$. Thus, controlling for voicing did not significantly change the results relative to the initial analysis.

To test whether the geminates followed the same consonant duration hierarchy (sonorant $<$ fricative $<$ non-continuant obstruents) when controlling for voicing, paired samples t-tests were conducted between each condition. Geminate sonorants were not found to be significantly different in duration than geminate fricatives, and were in fact numerically longer $\left(\mathrm{t}_{(10)}=\right.$ 1.77, $\mathrm{p}=0.11, \mathrm{~d}=0.44)$ and geminate non-continuant obstruents $\left(\mathrm{t}_{(10)}=6.54, \mathrm{p} 6.53 \mathrm{e}^{-5}, \mathrm{~d}=1.15\right)$, and geminate fricatives were shorter than geminate non-continuant obstruents $\left(\mathrm{t}_{(10)}=7.01, \mathrm{p}=3.66 \mathrm{e}^{-5}, \mathrm{~d}=1.63\right)$. 

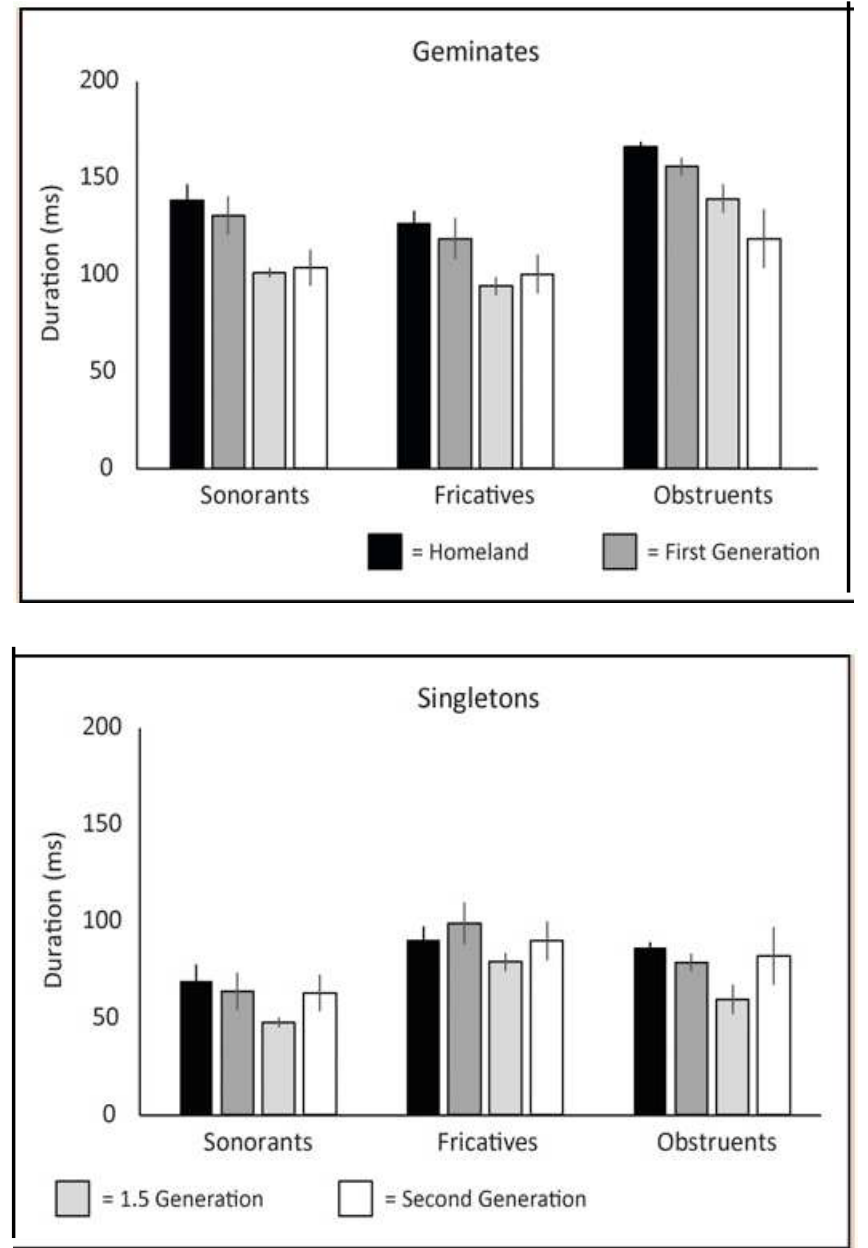

Figure 5. The impact of generation on mean duration while controlling for voicing. Mean consonant durations for voiced consonants only are depicted for geminates (left panel) and singletons (right panel), separated by manner. Mean duration decreased across successive generations, and did so more for geminates than for singletons. Error bars represent standard error.

Following up on the marginally significant interaction between generation and geminatesingleton contrast, an exploratory multiple regression was conducted with geminate-singleton contrast, age of arrival, and an interaction variable as predictors of mean duration, while controlling for voicing. Age of arrival was calculated as the chorological age each individual was upon arrival in Canada, and thus the homeland group was omitted. Using this more nuanced, continuous variable to describe age of arrival, results largely reflected the ANOVA using categorical age-of-arrival descriptors. The total model significantly predicted mean duration $\left(\mathrm{R}^{2}=0.65, \mathrm{~F}=26.92 . \mathrm{p}<0.001\right)$. Age of arrival was found to be a significant predictor of mean duration $(\beta=0.26, t=2.88, p=0.006$, partial- $R$
$=0.40)$, as was geminate-singleton contrast $(\beta=0.55$, $\mathrm{t}=4.29, \mathrm{p}<0.001$, partial- $\mathrm{R}=0.54)$. The interaction here was significant, $(\beta=0.27, t=2.08, p=0.04$, partial- $R=0.30$ ), with younger generations showing a smaller difference between duration of singletons and geminates (Figure 6). Thus, controlling for voicing did not change the overall pattern of results (see Fig 3), but clarified the role that Age of Arrival plays.

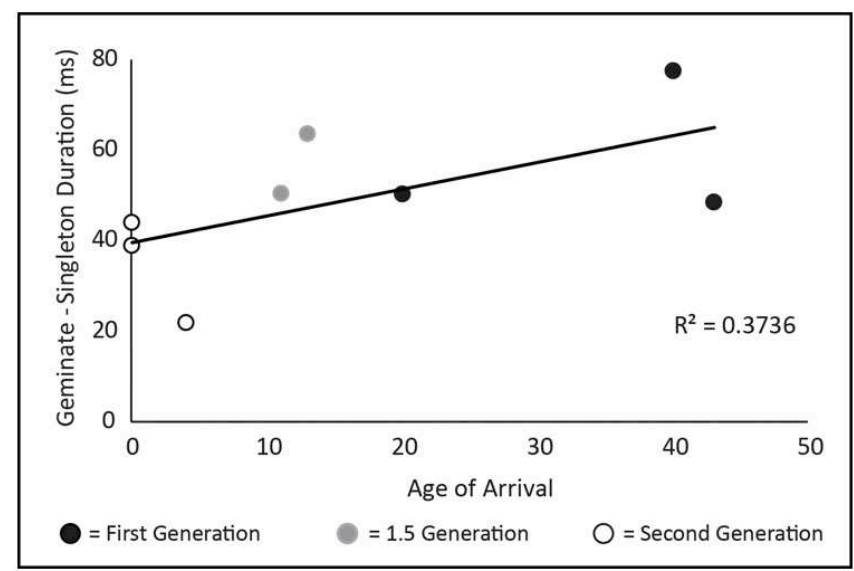

Figure 6. Age of arrival significantly predicts geminate-singleton differences in duration when voicing was controlled. The earlier the age at which an individual immigrated, the more attrition was observed, and the smaller the difference between geminate and singleton duration.

\subsection{The impact of generation on geminate- singleton overlap}

The initial 2-way ANOVA exploring the impact of generation and manner on overlap (see Analysis for details) yielded no significant main effects of manner $\left(F_{(1.16,11.25)}=0.93, p=0.38, \eta_{p}{ }^{2}=0.12\right)$, a significant effect of generation $\left(\mathrm{F}_{(3,7)}=5.88, \mathrm{p}=0.025, \eta_{\mathrm{p}}{ }^{2}=0.72\right)$, and no 2-way interaction between the two factors $\left(\mathrm{F}_{(1.16 \text {, }}\right.$ ${ }_{11.25)}=2.50, \mathrm{p}=0.13, \eta_{\mathrm{p}}{ }^{2}=0.52$; see Figure 7). Thus, overlap increased across successive generations, but did not vary across manner, nor did the impact of manner change across generations.

The follow-up 2-way ANOVA exploring the impact of generation and manner on overlap while controlling for voicing produced similar results (see Analysis for details). A significant effect of generation was observed $\left(F_{(3,7)}=5.88, p=0.025, \eta_{p}{ }^{2}=0.72\right)$. However, the analysis did not yield any significant main effect of manner $\left(\mathrm{F}_{(1.61,11.25)}=1.15, \mathrm{p}=0.34, \eta_{\mathrm{p}}{ }^{2}=0.14\right)$, and no 2-way 
interaction between the two factors was observed $\left(\mathrm{F}_{(4.82}\right.$ ${ }_{11.25)}=0.78, \mathrm{p}=0.58, \eta_{\mathrm{p}}^{2}=0.25$; see Figure 7). Thus, overlap increased across successive generations, but did not vary across manner, nor did the impact of manner change across generations when controlling for voicing.
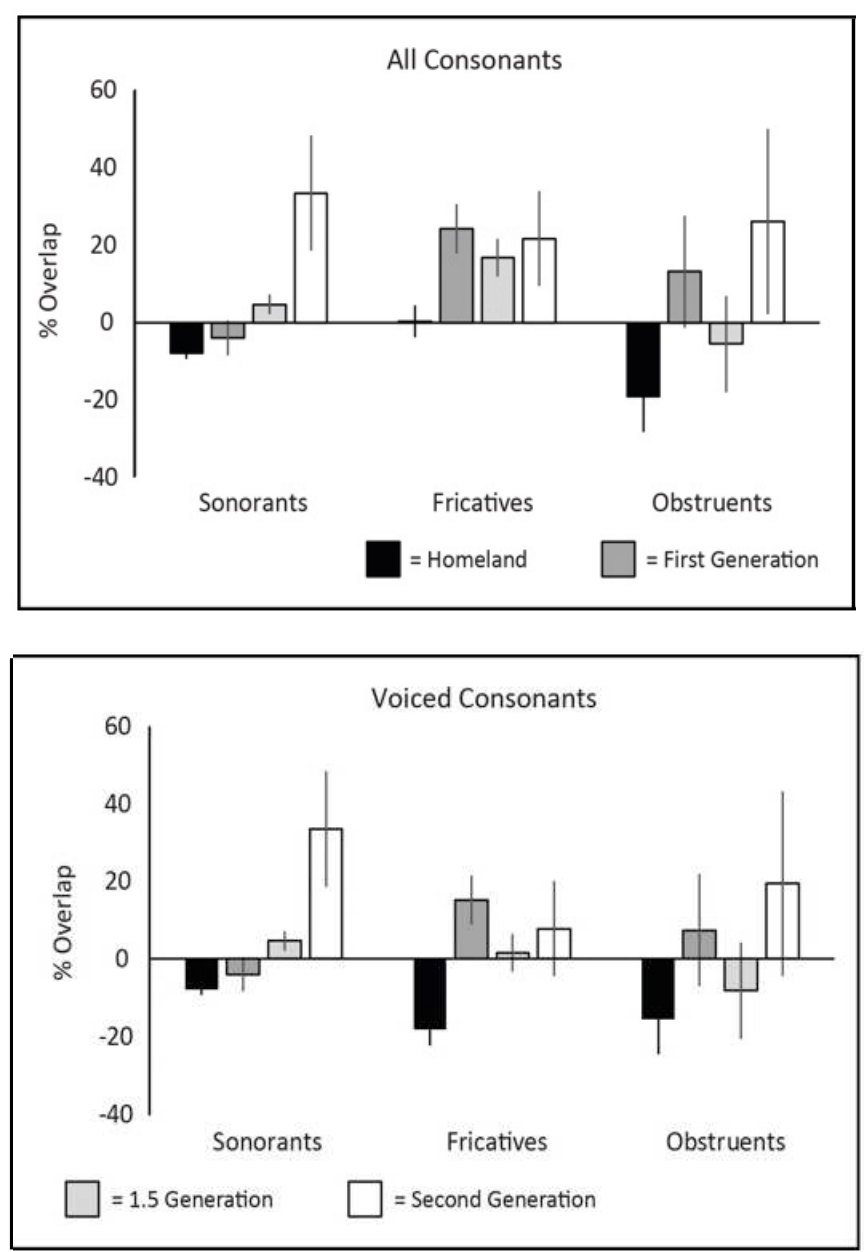

Figure 7. The impact of generation on geminate-singleton overlap. Overlap in duration of consonants is depicted for all consonants (left panel) and for only voiced consonants (right panel), separated by manner. Overlap increased across generation, indicating less of a difference between duration of geminates and singletons in younger generations. Negative overlaps are indicative of a gap such that the longest singletons were shorter than the shortest geminates. Neither manner nor voicing impacted overlap. Error bars represent standard error.

\section{Discussion}

In this study, we have examined the effect of manner of articulation on geminate change across various generations of Farsi-English bilinguals. We quantified attrition in terms of temporal reduction and percentage of degemination or overlap of geminates and singletons. In regard to the effect of generation of immigration, the results showed that all participants, regardless of their generation or age of arrival were able to produce geminates. However, as predicted, there was evidence of geminate consonant attrition across generations. Namely, geminates became shorter in each successive generation. Specifically, the following hierarchies were observed, in which geminate duration relative to singleton duration decreased following age of immigration: homeland > first generation > 1.5 generation $>$ second generation, and percentage overlap increased following generation of immigration: homeland $<$ first generation $<1.5$ generation $<$ second generation.

Previous studies such as Hrycyna et al. (2011) and Nodari, Celata \& Nagy (2016) also support the relevance of generation of immigration as a predictor of L1 attrition in bilinguals. Celata \& Cancila (2010) reported attrition in the perception of geminates across first and second generation Luchese-English speaking ItalianAmericans living in the U.S. Our study, however, is the first to report attrition in the production of geminates in an understudied immigrant community in Canada. The current research contributes to the body of literature on the effect of generation by considering a new group, which Rumbaut (2004) considers the 'bridge-builders', more 'bi-lingual' and more 'bi-cultural' than the first and second generations. What our results show is that this group exhibited a higher degree of attrition than the first generation but a lower degree of attrition than the second generation. We predicted that if the degree of attrition was actually an index of the degree of nativelikeness or foreign accent in Farsi, the 1.5 generation group would be categorized as less native-like than the first generation and more native-like than the second generation. Future studies can determine whether the degree of geminate attrition in the speech of bilinguals is a predictor of the degree of the participants' nativelikeness in Farsi by native-speaker judges.

Consistent with typological patterns we had predicted that geminate attrition would be constrained by universal phonetic principles, in which manner (e.g., Blevins, 2004; Podesva, 2002; Steriade, 1982; Taylor, 
1985) and voicing (e.g., Elmedlaoui, 1993; Kawahara, 2007) would be predictors of geminate consonant attrition across the three generations. There was evidence suggesting that universal phonetic factors determine geminate realization by Farsi-English bilinguals. Firstly, geminate consonant durations were dependent upon manner: sonorants $<$ fricatives $<$ non-continuant obstruents. Secondly, voiced geminates were shorter than their voiceless counterparts. It should be noted here that the difference was not found between sonorant and fricative duration when accounting for voicing. However, despite our predictions, there was no evidence of either manner or voicing predicting the degree of attrition across geminate consonants, suggesting that more marked geminates are not more susceptible to change across generations in contact situations. These findings are inconsistent with Sorianello's (2014) results of L2 geminate productions that showed that consonant length is better preserved by L2 learners of Italian in phonetic environments that facilitate the articulation of long segments or where long segments are acoustically more salient. However, the lack of evidence for the effect of manner and voicing on attrition in our study may be due to a small sample size.

We also believe that the effect of positional factors and prosody (e.g., stress) on geminate attrition merits investigation. Previously, these factors have predicted consonant weakness on a fortis lenis continuum (see Lavoie, 2015 for more details). Colantoni \& Steele (2007), and Rafat (2011) also reported a positional asymmetry attributed to acoustic prominence in L2 production. Additionally, Rafat (2011) discussed positional differences in L2 production patterns in lieu of phonological memory.

Here, we have considered the term attrition broadly to include differences across generations in a contact situation between Farsi and English in immigrants living in Canada. While there is evidence of geminate-singleton consonant length reduction across generations, shorter realizations of geminates might be due to different reasons within each generation. That is, contact with English might be a crucial factor that results in attrition in the first generation; however, in generation 1.5,language dominance might act as the main factor (e.g., Montrul \& Potowski, 2007; Polinsky, 2007; SilvaCorvalán, 2003), and in the second generation, language dominance and incomplete acquisition may be the reason for shorter values, also commonly referred to as heritage speakers (e.g., Montrul, 2008, 2010; Montrul \& Ionin, 2010). We hypothesize that the geminate productions of the second generation group will pattern more with L2 learners of Farsi (e.g., Cornwell \& Rafat, 2016) than the first or the 1.5 generations. Future studies can compare geminate-singleton consonant length contrast production reported in this study with L2 learners of Farsi.

Finally, in this article we have examined the changes in the production of a phonologically marked feature. Marked phenomena are perceptually less salient, are more difficult to produce, or require more precision in their articulation (e.g., Solé, 1998; Hayes, Kirchner \& Steriade, 2004). These phenomena pose more difficulties for bilinguals and are acquired later by L2 learners (e.g., Major, 2001). The geminate-singleton length contrast has also been shown to be difficult to acquire by L2 learners (e.g., Han, 1992; Mah and Archibald, 2003; Costamagna, Montilli \& Ricci, 2014; Sorianello, 2014). Here we have shown that a marked contrast can also undergo attrition in bilingual speakers in a language contact situation. In the future, it would be interesting to compare the degree of attrition of the geminate-singleton length contrast to an unmarked contrast in the same bilingual groups. Consistent with second language phonological acquisition patterns and language universal principles, we predict that marked contrasts such as geminates will be more likely to undergo attrition than unmarked ones.

While there are a number of prominent models of L2 phonological acquisition (Flege, 1987, 1995; Brown, 1998; Best \& Tyler, 2007; Escudero, 2005; Colantoni \& Steele, 2008), so far Flege's Speech Learning Model $(1987,1995)$ has been the main if not the only model applied to bilingualism. The SLM outlines the potential bidirectional influence of the L1 and L2 sounds and considers the effect of the acoustic/phonetic distance between the L1 and the L2 sounds. That is, it claims that the smaller the distance between the L1 and the L2 the stronger the possibility of equivalence classification 
and merger. Although there was no evidence to suggest that manner or voicing are predictors of attrition, we believe the effect of universal phonetic factors should be further investigated and possibly incorporated into models of first language attrition.

The findings in this study also suggest that attrition of the geminate-singleton length contrast and the shift towards English is a gradual process. We predict that the process of degemination might become complete, albeit, in successive generations or later on during the life span of the participants examined in this study. We also think the social factors mentioned by Hrycyna et al. (2011), such as the cohesiveness of a community, having enough opportunity for casual speech, the size of a community, and attitude towards a particular variety of a native or heritage language may also determine the rate of attrition and are worth investigating further.

\section{Conclusion}

In sum, we have investigated phonological attrition of geminate-singleton consonant length attrition in a language contact situation across three generations of Farsi-English bilinguals living in Canada. We have found evidence of attrition of this phonological contrast and a gradual shift towards English in the production of our participants. Specifically, we found that generation is a predictor of the degree of phonological attrition, in which the degree of attrition increases in successive generations. While there was evidence to suggest that more marked geminate consonants were shorter than less marked ones, there was no evidence that either manner or voicing predicted the degree of attrition across generations. This might be due to a small sample size and we believe the effect of both universal phonetic factors and social factors in phonological attrition merits further investigation.

\section{Funding}

This work was supported by the Small Academic Development Fund [RES001633]

\section{Notes}

1. Some of the other acoustic cues for gemination include increased linguopalatal contact (Fougeron \& Keating, 1997; Kochetov, 2012) preceding vowel duration (Han, 1994; Hansen, 2004), CV ratio (e.g., Warner \& Arai, 1999), amplitude of flanking vowels (Kawahara, 2007), and intensity (Al-Tamimi \& Khattab, 2015). In this paper, we will be focusing on examining consonant duration).

2. Our intuition is that in addition to being phonologically contrastive, gemination can also be phonetic/noncontrastive. For example, similarly to Italian (Borrelli, 2013) syntactic doubling in Farsi (<che ghadr $>$ [ $\int \mathrm{e}$ G:adr] 'how much') is very frequent in less formal registers. Also pseudo-geminates are attested due to assimilation processes. For example, [bæstæni] 'ice cream' can be produced as [bæ.'s:æ.ni].

\section{References}

Al-Tamimi, J., \& Khattab, G. (2015). Acoustic cue weighting in the singleton vs geminate contrast in Lebanese Arabic: The case of fricative consonants. Journal of the Acoustical Society of America, 138, 344360.

Bailey, C.-J N. (1983). The patterning of sonorant gemination in English lects. In Fasold, R. W. (ed.), Variation in the Form and Use of Language: $a$ Sociolinguistics Reader (pp. 175-185). Washington DC: Georgetown University Press.

Baker, W., \& Trofimovich, P. (2005). Interaction of nativeand second-language vowel system(s) in early and late bilinguals. Language and speech, 48, 1-27.

Best, C. T., \& Tyler, M. D. (2007). Nonnative and second language speech perception: Commonalities and complementarities. In M. J. Munro \& O. S. Bohn (eds.), Second language speech learning: The role of language experience in speech perception and production (pp. 13-34). Amsterdam: John Benjamins.

Blevins, Juliette. (2004). Evolutionary Phonology. Cambridge: Cambridge University Press.

Borrelli, D. A. (2013). Raddoppiamento sintattico in Italian: a synchronic and diachronic cross-dialectical study. Routledge.

Boersma, P., \& Weenink, D. (2012). Praat: doing phonetics by computer [Computer program]. Version 5.3. 39.

Brown, C. A. (1998). The role of the L1 grammar in the acquisition of segmental structure. Second Language Research, 14, 139-193.

Bybee, J. (2001). Phonology and language use. Cambridge: Cambridge University Press. 
Bybee, J., \& Hopper, P. (2001). Frequency and the emergence of linguistic structure. Amsterdam: John Benjamins.

Bullock, B. E., \& Gerfen, C. (2004). Frenchville French: A case study in phonological attrition. International Journal of Bilingualism, 8(3), 303-320.

Cao, X. (June, 2016). L1 Tone attrition among bilinguals in an L2 speaking environment. Third Internation Conference on Language Attrition, University of Essex.

Celata, C., \& Cancila, J. (2010). Phonological attrition and the perception of geminate consonants in the Lucchese community of San Francisco (CA). International Journal of Bilingualism, 14, 1-25.

Chang, C. E. (2012). Rapid and multifaceted effects of second-language learning on first-language speech production. Journal of Phonetics, 40, 249-268.

Chung, S. (1997). Acculturation and identification in the" 1.5 generation" of Korean immigrants. Cultural Perspectives on Developmental Psychology. Available at: http://ematusov.soe.udel.edu/final.paper.pub/_pwfsfp /000000c3.htm.

Cohn, A. C., Ham, W. H., \& Podesva, R. J. (1999, August). The phonetic realization of singletongeminate contrasts in three languages of Indonesia. In Proceedings of ICPhS (Vol. 14, pp. 587-590).

Colantoni, L., \& Steele, J. (2007). Acquiring /R/ in context. Studies in Second Language Acquisition, 29, 381-406.

Colantoni, L., \& Steele, J. (2008). Integrating articulatory constraints in models of L2 phonological acquisition. Applied Psycholinguistics, 29, 1-46.

Cornwell, S. \& Rafat, Y. (June, 2016). Heritage Dutch interdental fricative production. Paper presented at the 8th International Symposium on the Acquisition of Second Language Speech (New Sounds). Aarhus University, Denmark.

Costamagna, L., Montilli, C., \& Ricci, I. (2014). The role of prosodic features in the acquisition of consonant gemination by Chinese learners. Consonant gemination in first and second language acquisition (pp. 47-82). Pisa: Pacini editore

De Leeuw, E., Mennen, I., \& Scobbie, J. M. (2013). Dynamic systems, maturational constraints and L1 phonetic attrition. International Journal of Bilingualism, 17, 683-700.

Delattre, P. (1968). Consonant gemination in four languages: an acoustic, perceptual and radiographic study. The General Phonetic Characteristics of Languages: Final Report. Available at: https://archive. org/details/ERIC_ED034994.
Elmedlaoui, M. (1993). Gemination and Spirantisation in Hebrew, Berber, and Tigrinya: a Fortis-Lenis Module Analysis. Linguistica Communicatio, 1, 121-176.

Escudero, P. (2005). Linguistic perception and second language acquisition: Explaining the attainment of optimal phonological categorization. LOT Dissertation Series 113. Utrecht: LOT.

Flege, J. E. (1987). The production of 'new' and 'similar' phones in a foreign language: evidence for the effect of equivalence classification. Journal of Phonetics, 15, $47-65$.

. (1995). Second language speech learning: Theory, findings, and problems. In W. Strange (ed.), Speech perception and linguistic experience: Issues in crosslinguistic research, pp. 233-277. Timonium, MD: York Press.

Flege, J. E., Bohn, O. S., \& Jang, S. (1997). Effects of experience on non-native speakers' production and perception of English vowels. Journal of phonetics, 25(4), 437-470

Fougeron, C., \& Keating, P. (1997). Articulatory strengthening at edges of prosodic domains. Journal of Acoustical Society of America, 101, 3728-3740.

Guion, S. G. (2003). The vowel systems of QuichuaSpanish bilinguals: Age of acquisition effects on the mutual influence of the first and second languages. Phonetica, 60, 98-128.

Han, M.S. (1992). The timing control of geminate and single stop consonants in Japanese: a challenge for nonnative speakers. Phonetica, 49, 102-27.

(1994). Acoustic manifestations of mora timing in Japanese. The Journal of the Acoustical Society of America, 96(1), 73-82.

Hansen, B. (2004). Persian geminate stops: Effects of varying speaking rate. In Agwuele, Augustine, Warren, Willis, \& Park, Sang-Hoon (eds.), Proceedings of the 2003 Texas Linguistics Society Conference: Coarticulation in Speech Production and Perception (pp. 86-95). Somerville, MA: Cascadilla Proceedings Project.

Hassan, Z. M., Payne, E. (2008) "Post-lexical Geminates in Syrian Arabic: Preliminary results from a crossdialectal investigation." British Association of Academic Phoneticians Colloquium, University of Sheffield.

Hayes, B., Kirchner, R., \& Steriade, D. (2004). Phonetically based phonology. Cambridge University Press.

Hayes, B., \& Steriade, D. (2004). Introduction: The phonetic bases of phonological markedness. In B. Hayes, R. Kirchner \& D. Steriade (eds.), Phonetically- 
Based Phonology, pp. 1-33. Cambridge: Cambridge University Press.

Hrycyna, M., Lapinskaya, N., Kochetov, A., \& Nagy, N. (2011). VOT drift in 3 generations of heritage language speakers in Toronto. Canadian Acoustics, 39, 166-167.

Jaeger, J. (1978). Speech aerodynamics and phonological universals. In Editors Names (eds.), Proceedings of the $4^{\text {th }}$ Annual meeting of the Berkeley Linguistics Society, pp. 312-329. Berkeley, California: Berkeley Linguistics Society.

Khattab, G., \& Al-Tamimi, J. (2014). Geminate timing in Lebanese Arabic: the relationship between phonetic timing and phonological structure. Laboratory Phonology, 5(2), 231-269.

Kawahara, S. (2007). Sonorancy and geminacy. In L. Bateman, A. Werle, M. O'Keefe and E. Reilly (eds.), University of Massachusetts Occasional Papers in Linguistics 32: Papers in Optimality Theory III, pp. 145-186. Amherst: GLSA.

Kaye, A. (2005). Gemination in English. English Today, 21, 43-55.

Kochetov, A. (2012). Linguopalatal contact differences between Japanese geminate and singleton stops. Canadian Acoustics 40, 28-29.

Köpke, B. \& Schmid M. S. (2004). Language attrition: the next phase. First Language Attrition: Interdisciplinary perspectives on methodological issues (Schmid, M. S.,

Köpke, B., Keijzer, M., Weilemar, L.) (pp. 1-43). Amsterdam/Philadelphia: John Benjamins Publishing Company.

Ladefoged, P. (1999). American English. In Editors Names (eds.), Handbook of the International Phonetic Association (pp. 41-44). Cambridge: Cambridge University Press.

Lavoie, L. M. (2015). Consonant strength: Phonological patterns and phonetic manifestations. Routledge.

Maddieson, I. (1984). Patterns of sounds. Cambridge: Cambridge University Press.

Mah, J. and Archibald, J. (2003). Acquisition of L2 length contrasts. In Liceras, J.M., Zobl, H., \& Goodluck, H., (eds.), Proceedings of the $6^{\text {th }}$ Generative Approaches to Second Language Acquisition Conference, pp. 208-212. Somerville, MA: Cascadilla.

Mahootian, S. (1997). Persian. London: Routledge.

Major, R. C. (1986). The ontogeny model: Evidence from L2 acquisition of Spanish r. Language Learning, 36, 453-504.

(1992). Losing English as a first language. The Modern Language Journal, 76(2), 190-208.
. (2001). The ontogeny and phylogeny of second language phonology. London: Lawrence Publishers.

Markus, E., Lippus, P., Pajusalu, K., \& Teras, P. (2012). Three-way opposition of consonant quantity in Finnic and Saamic languages. In Nordic prosody: proceedings of the 11th conference, Tartu (pp. 225-234).

Mayr, R., Price, S., \& Mennen, I. (2012). First language attrition in the speech of Dutch-English bilinguals: The case of monozygotic twin sisters. Bilingualism: Language and Cognition, 15, 687-700.

Mennen, I. (2004). Bi-directional interference in the intonation of Dutch speakers of Greek. Journal of Phonetics, 32, 543-563.

Mennen, I., Mayr, R., \& Price, S. (2011). L1 attrition of prosody: The case of bilingual monozygotic twin sisters. Ms., Bangor University \& Cardiff Metropolitan University.

Montrul, S. (2008). Incomplete acquisition in bilingualism: Re-examining the age factor. Amsterdam, the Netherlands: John Benjamins.

(2010) How similar are L2 learners and heritage speakers? Spanish clitics and word order. Applied Psycholinguistics, 31, 167-207.

Montrul, S., \& Ionin, T. (2010). Transfer effects in the interpretation of definite articles by Spanish heritage speakers. Bilingualism: Language and Cognition, 13, 449-473.

Montrul, S., \& Potowski, K. (2007). Command of gender agreement in school-age Spanish-English Bilingual Children. International Journal of Bilingualism, 11(3), 301-328.

Nespor, M., \& Vogel, I. (1986). Prosodic phonology. Foris: Dordrecht (1986 [1997]).

Nodari, R., Celata, C., \& Nagy, N. (July, 2016). Immigrants' speech: is phonetic attrition a necessary precondition for phonological attrition to occur? Paper presented at the Third International Conference on Language Attrition, Colchester, UK.

Obrecht, O. H. (1965). Three experiments in the perception of geminate consonants in Arabic. Language and Speech, 8, 31-41.

Ohala, J. (1983). The origin of sound patterns in vocal tract constraints. In P. MacNeilage (ed.), The Production of Speech (pp. 189-216). New York: Springer Verlag.

Payne, E. (2005). Phonetic variation in Italian consonant gemination. Journal of the International Phonetic Association, 35(2), 153-181.

Peng, S. (1993). Cross-language influence on the production of Mandarin /f/ and /x/ and Taiwanese /h/ 
by native speakers of Taiwanese Amoy. Phonetica, 50, 245-260.

Podesva, R. (2002). Segmental contrasts on geminates and their implications for typology. A handout for a talk given at the LSA Annual Meeting.

Polinsky, M. (2007). Incomplete acquisition: American Russian. Journal of Slavic Linguistics, 14, 191-262.

Rafat, Y. (2008). The acquisition of allophonic variation in Spanish as a second language. In S. Jones (ed.), Proceedings of the Annual Conference of the Canadian Linguistic Association (pp.1-15). Vancouver, BC.

(2010). A socio-phonetic investigation of rhotics in Persian. Iranian Studies, 43, 667-682.

(2011). Orthography-induced transfer in the production of novice adult English-speaking learners of Spanish (Doctoral dissertation, University of Toronto).

. (2015). The interaction of acoustic and orthographic input in the L2 production of assibilated/ fricative rhotics. Applied Psycholinguistics, 36, 43-64.

Roach, P. (2000). English Phonetics and Phonology. Cambridge: Cambridge University Press.

Rumbaut, R. (2004). Ages, life stages, and generational cohorts: Decomposing the immigrant first and second generations in the United States. International Migration Review, 38: 1160-1205.

Silva-Corvalán, C. (2003). Linguistic consequences of reduced input in bilingual first language acquisition. In S. Montrul \& F. Ordóñez (Eds.), Linguistic theory and language development in Hispanic languages (pp. 375-397). Somerville, MA: Cascadilla Press.

Solé, M. (1998). Phonological Universals: Trilling, voicing and frication. Berkeley Linguistics Society, 24, 427-442.

Sorianello, P. (2014). Italian geminate consonants in L2 acquisition. In L. Costamagna \& C. Celata (eds.), Consonant gemination in first and second language acquisition (pp. 25-46). Pisa: Pacini Editore.

Schmid, M. S. (2002). First Language Attrition, Use and Maintenance: the Case of German Jews in Anglophone Countries. Amsterdam: John Benjamin.

Steriade, D. (1982). Greek Prosodies and the Nature of Syllabification. Ph.D. dissertation, MIT.

Tan, T. X. (2016). Emotional and Behavioral Disorders in 1.5 th Generation, 2nd Generation Immigrant Children, and Foreign Adoptees. Journal of immigrant and minority health, 18(5), 957-965.

Taylor, M. (1985). Some patterns of geminate consonants. The University of Chicago Working Papers in Linguistics, 1, 120-129.
Ulbrich, C. \& Ordin, M. (2014). Can L2-English influence L1-German? The case of post-vocalic /r/. Journal of Phonetics, 45, 26-42.

Warner, N \& Arai, T. (1999). Japanese mora-timing: A review. Phonetica, 58, 1-25.

Wolfram, W. \& Schilling-Estes, N. (1998). American English: Dialects and variation. Malden, MA: Basil Blackwell.

Recebido em: 09/05/2017

Aceito em:13/07/2017 


\section{APPENDIX}

Table 1. Characteristics of participants.

\begin{tabular}{|c|c|c|c|c|c|}
\hline \multirow{2}{*}{ Generation } & Participant & Gender & Age & Age of arrival & Language dominance \\
\hline \hline \multirow{2}{*}{1} & A & Male & 61 & 40 & Balanced bilingual \\
\cline { 2 - 6 } & B & Female & 66 & 43 & Farsi-dominant \\
\cline { 2 - 6 } & C & Female & 60 & 20 & Balanced bilingual \\
\hline \multirow{2}{*}{1.5} & D & Male & 38 & 11 & English-dominant \\
\cline { 2 - 6 } & E & Male & 30 & 13 & English-dominant \\
\cline { 2 - 6 } & F & Female & 33 & 0 & English-dominant \\
\cline { 2 - 6 } & G & Male & 29 & 0 & English-dominant \\
\hline \multirow{2}{*}{ Homeland } & I & Female & 55 & N/A & Farsi Monolingual \\
\cline { 2 - 6 } & J & Male & 54 & N/A & Farsi Monolingual \\
\cline { 2 - 6 } & K & Female & 56 & N/A & Farsi Monolingual \\
\hline
\end{tabular}

